\title{
Research on Technology and Application of Buried Faults Identification in Urban Underground Space
}

\author{
Hongzhao $\mathrm{Li}^{1}$, Xianhong $\mathrm{Wu}^{2}$, Changli Liu ${ }^{1}$, Zhaoyang $\mathrm{Li}^{3^{*}}$ \\ ${ }^{1}$ Institute of Hydrogeology and Environmental Geology, Chinese Academy of Geological Sciences, \\ Shijiazhuang,Hebei Province, China \\ ${ }^{2}$ Airborne Survey and Remote Sensing Centre of Nuclear Industry, Shijiazhuang,Hebei Province, China \\ ${ }^{3}$ Institute of Environment and Resource, Shijiazhuang College, Shijiazhuang, Hebei Province, China \\ *CorrespondenceAuthor.
}

\begin{abstract}
With theurbanization rate's rising and three-dimensional expansion and development of urban, the identification of underground buried faults has become the key factor of earthquake risk in urban underground space and surface area. As a typical method of detecting blind faults in underground space, shallow seismic prospecting technology plays an important role in judging and avoiding potential risks such as underground faults in the process of urban expansion and site selection. In this paper, shallow seismic prospecting technology is adopted, and optimized processing technologies such as parameter test, tomographic correction, pre-stack denoising, fidelity and consistency processing, correction iteration, migration imaging, and time-depth relationship deduction are adopted. Underground faults are identified and interpreted in the studied urban area, and fault risk assessment is carried out based on fault characteristics, scale, distribution and overlying strata, thus providing suggestions for regional pattern and construction of urban planning.
\end{abstract}

Keywords: Urban underground, Shallow seismic prospecting, Buried Faults

\section{Introduction}

1.1Research background

As the main form of urban geological disasters, earthquake disasters caused by urban underground fault activities often bring huge economic losses and casualties to urban towns and related areas, such as the Northridge earthquake in Los Angeles in 1994, the Kobe earthquake in 1995, the Taiwan earthquake in 1999, the Wenchuan earthquake in 2008, the New Zealand earthquake in 2010, the Haiti earthquake in 2010 and the Nepal earthquake in 2015, etc[1-11]. With the improvement of urbanization rate, the stable development of social economy and the limited construction land, the development and utilization of urban three-dimensional space above and below ground has become the main measure for the construction and development of large and medium-sized cities. At the same time, the losses of urban geological disasters account for about $90 \%$ of the global earthquake disaster losses[12]. Therefore, we should strengthen the research on the detection and identification of urban underground faults[13-16], effectively grasp the blind faults, activity attributes and distribution characteristics of urban underground faults, and evaluate the potential geological safety risks in serving urban planning and urban construction[10,17], so as to avoid the destructive effect of earthquake disasters caused by urban underground faults as much as possible[18-23], and further improve the safety of future urban construction areas[24-31], building types and building layout.

1.2 Research progress of urban underground hidden strata identification

At present, the widely used underground fault detection technology is to use various geophysical techniques, such as seismic prospecting, multipole DC electrical exploration, ground penetrating radar, cross-well seismic and electromagnetic imaging and high-precision gravity measurement, etc.[32]. However, the increasingly complex 
natural geological environment and human factors in urban areas, such as various types of electromagnetic waves, signal towers, roads, bridges and complex reinforced concrete structures in buildings make the traditional geological detection methods such as electromagnetic detection technology and electrical detection technology be interfered. The shallow seismic detection technology can obtain underground geotechnical physical parameters and reconstruct underground strata and structural images without drilling holes to destroy the surface structure through optimization schemes such as seismic wave selection, parameter correction and data processing. At the same time, it has high detection efficiency and accuracy, and is suitable for urban areas with complex environment[33]. For example, Demanet and others tried to detect and identify the distribution of active faults in the field by using different geophysical techniques such as electrical prospecting, electrical tomography, ground penetrating radar and high-resolution reflection seismic profiling, and compared the detection results with the borehole data results, pointing out that the high-resolution shallow seismic method has higher accuracy and applicability than other geophysical methods[34]. Kaiser et al.[35] used high-resolution shallow seismic method combined with field geological outcrop observation to detect faults in New Zealand Alps, and determined the distribution and historical activities of faults. Barnes and Pondard used the high-resolution reflection seismic method to determine the slip rate of the Wairau fault in New Zealand and determine the activity of the fault [36]. Gu et al. re-detected and identified Benchahe fault by using high-resolution shallow seismic method. They determined that Benchahe fault is not necessarily a single fault, but a fault zone formed by the combination of two northward dipping faults, and further determined the strike and dip angle of the fault[37]. Liang et al. used high-resolution shallow seismic method to detect and identify blind faults in the Yellow River, determine the distribution and activity of faults, and predict the possible geological safety risks[38]. Onyebueke et al. used the high-resolution reflection seismic method to detect and investigate the active faults in Nilsley Nature Reserve, South Africa, and accurately identified and studied the regional active faults [39].

To sum up, shallow seismic method can avoid signal interference and accurately detect and identify the distribution and activity of blind faults. Therefore, based on shallow seismic method and optimized experimental scheme, this paper identifies and interprets blind faults in typical urban areas, with a view to providing reference for urban planning and construction layout.

\section{II.Overview of the Study Area}

\subsection{Topography}

The study area is a prefecture-level city with alluvial plains and low hills and hills. The Tan-Lu fault zone and its adjacent areas are slightly higher and are NNE-trending micro-uplift areas, with hills and hillsides distributed continuously (mainly on the north side of the waste Yellow River). On the south side of the waste Yellow River, it is mainly a low-lying plain with an elevation below $20 \mathrm{~m}$. The water system in the area is well developed, with natural rivers and artificial ditches interlaced into a network. See Figure 1.

\subsection{Stratum}

Archean-Lower Proterozoic

Taishan Group: mainly composed of biotite plagioclase gneiss, green shade biotite plagioclase gneiss, amphibolite, migmatizedbiotite plagioclase gneiss, plagioclase migmatite, K-feldspar migmatite and monzonitemigmatite.

Jiaodong Group: a set of regional metamorphic rock series. It is mainly composed of biotite plagioclase gneiss, which is migmatized in different degrees.

\section{Mesozoic Era}

Cretaceous

Lower Qingshan Formation (K1q): the upper part is composed of dark gray and purplish red andesite basalt, basaltic andesite and breccia lava, with silt, fine sandstone and mudstone locally.

Upper Wangshi Formation (K2w): the upper part is brick red and dark red sandstone and conglomerate, which 
appear rhythmically. Some conglomerates are lenticular, with shale, thin argillaceous limestone and copper-bearing fine-grained sandstone locally. The lower part is purplish red and deep brick red conglomerate and glutenite, locally mixed with powder, fine sandstone and mudstone.

\section{Cenozoic Era}

\section{Paleogene}

GuanzhuangFormation (E2g): the upper part is purplish red, purplish gray, greenish brown siltstone, shale and sandy shale, with a small amount of conglomerate, glutenite or plant fossil fragments and coal lines, and the sandstone often has horizontal or cross bedding; the lower part is purplish red mixed with grayish green medium-fine sandstone, containing gravelly medium-coarse sandstone, shale mixed with conglomerate, which is mostly angular, poorly sorted and rounded. The sandstone often has wavy and cross bedding.

Dawenkou Formation (E2-3dw): a set of sand-shale deposits rich in gypsum and salt, and its lithology can be divided into three parts: gray, gray-green, brown-gray, gray-red calcareous mudstone, clay rock and siltstone at the upper part, mixed with a small amount of marl or medium coarse sandstone, sometimes containing gypsum at the bottom, with micro-bedding and horizontal bedding developed; the middle part is gray, gray-green, purplish red, mixed with gray-white dark red silty fine sandstone and sandy mudstone, mixed with a small amount of gravelly coarse sandstone; the lower part is purplish red and grayish green siltstone with a small amount of gypsum, and the local sandstone shows oblique bedding or horizontal bedding.

XiacaowanFormation (N1x): lithology is roughly divided into two parts. The upper part is grayish yellow and pink calcareous silty mudstone, grayish green calcareous mudstone and calcareous mudstone interbedded with gray marl lens. The bottom part is grayish white calcareous conglomerate, grayish yellow and brownish yellow sandstone and calcareous sandstone, and the lower is mainly grayish green calcareous mudstone and calcareous silty mudstone interbedded with light gray gravelly calcareous medium sandstone and pink calcareous sandstone; the lower part is grey, brownish yellow fine sandstone, gravelly fine sandstone and argillaceous siltstone, mixed with grey, grayish green mudstone and silty mudstone, and the bottom part is glutenite.

SuqianFormation (N2s): it mainly consists of gray-white, grayish green medium coarse sand, grayish green, brownish yellow clay, gravelly loam and grayish yellow, brownish yellow fine sand layer.

\section{Quaternary}

Douchong Formation (Q1d): yellow-gray and gray-white clay silty fine sand, brown-yellow, brown-yellow and gray-white medium coarse sand and medium fine sand, with gravel or sand-gravel layer locally, large-scale oblique bedding developed, mainly fluvial facies deposits.

Bogang Formation (Q2b): a set of red strata subjected to hygrothermal action, the upper part of which is brownish red and brownish yellow sub-clay, with little or no reticulation, and local gravel; the lower part is brownish red mud gravel, which is mixed with loam, and the gravel is sub-round and sub-angular.

Qizui Formation $(\mathrm{Q} 3 \mathrm{q})$ : it is divided into three parts. The upper part is mainly brownish yellow, brownish brown silty loam, light brown silty clay, containing calcareous nodules and ferromanganese nodules. Calcareous nodules are often rich in integrated layers; the middle part is grayish yellow, gray powder and fine sand; the lower part is mainly composed of yellow-brown and orange gravel layer and gravel-bearing loam. The gravel is angular and often mixed with mud.

Holocene series (Q4): mainly a set of yellow-gray, gray-black, brownish-yellow sand, argillaceous sedimentary clay or sand. 


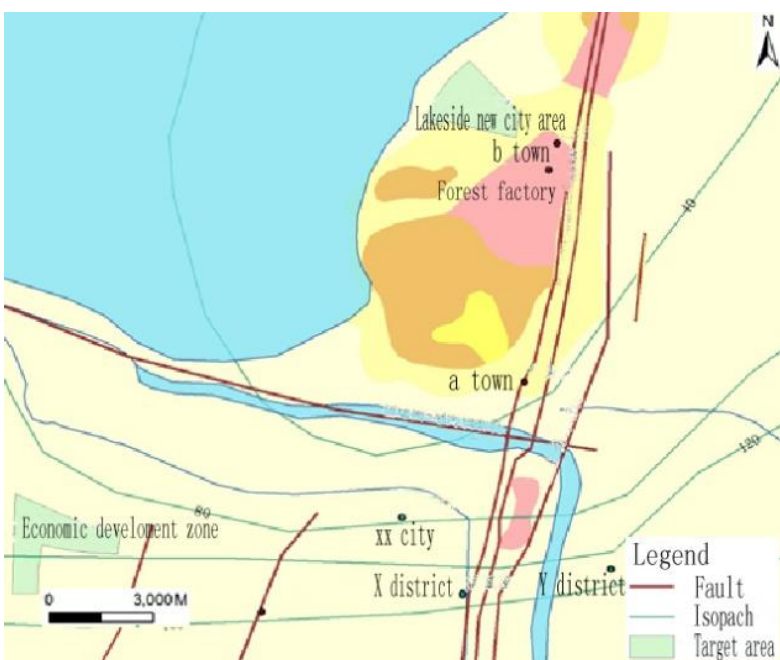

Fig1: Schematic diagram of structure and Quaternary thickness in the study area

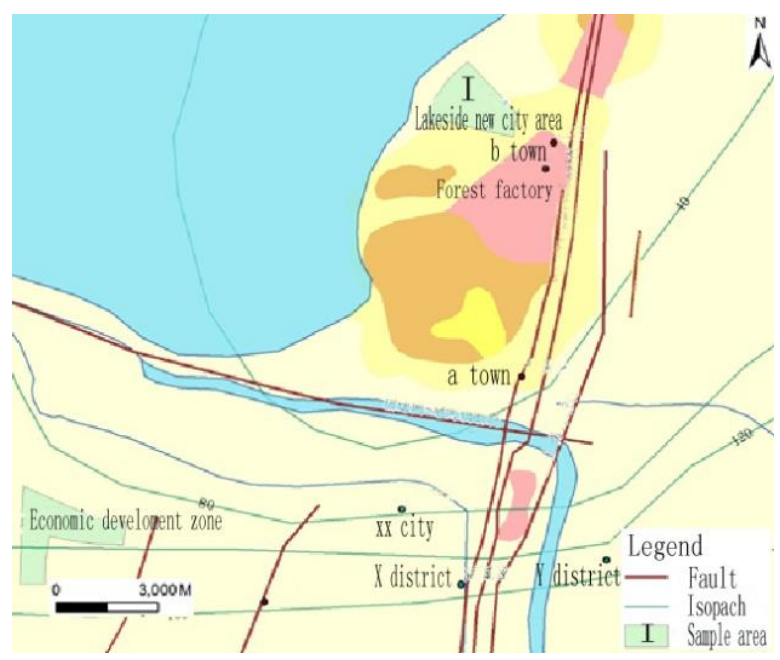

Fig2: Schematic diagram of the location of the test target sample area (I)

\subsection{Regional geological structure}

The study area is located at the junction of North China landmass and Sulu orogenic belt, and its boundary is the Tan-Lu fault zone passing through the urban area. The northern part of the study area is a low mountain and hilly area, with mountains clustered and undulating terrain, and fault activity has a great impact on the northern region; compared with the northern part, the southern part is flat, with many lakes and dense river networks. Since the neotectonic movement, the area has been continuously settled, and the average thickness of Quaternary sediments is over $100 \mathrm{~m} \mathrm{~m}$. Most of the fault zones in this area are concealed structures. However, the fault zone has an impact on the development of water system, basins and lakes in this area. At the same time, the metamorphic basement formed in Archean and Proterozoic in North China block has an important impact on the development of the structure, and the subsequent structural outline is basically controlled by the ancient basement. In early Paleozoic and late Paleozoic, tectonic deformation and magmatic activity were weak, which was a relatively stable platform stage. It entered a relatively active stage after Mesozoic and Cenozoic.

In recent years, the urban construction of the prefecture-level city studied has developed rapidly. In this paper, Hubin New District I, a new urban area in the northern part of the city, is selected as the test target sample area (see Fig.2), and the characteristics and risks of faults in the target area are determined by shallow seismic prospecting.

\section{III.Seismic Geological Conditions}

\subsection{Surface conditions}

The survey area has flat terrain, dense buildings, villages and factories, complex surface conditions, dense shops and villages near some survey lines, large road traffic and mixed traffic. The above terrain and ground objects bring great difficulties to geophone placement and data acquisition.

\subsection{Shallow seismic geological conditions}

The Quaternary in the working area is distributed in a large area, with a thickness of about 50 140m. The ground surface is unconsolidated grayish yellow, yellowish brown silt and silty clay. At the same time, the underlying bedrock has a shallow buried depth and obvious seismic wave impedance interface, which can form a reflection wave with strong energy. The excitation horizon is easy to excite, with good excitation conditions.

\subsection{Geophysical conditions}


There are obvious wave impedance differences between soil and sand layer, sand layer and clay, clay and sandstone in the study area, and there are strong reflection information in the surface data, as shown in Table 1.

When there are obvious differences in wave impedance and wave velocity between Quaternary overburden and bedrock, and each layer has a certain thickness, the reflection interface can be formed; when there are faults, fracture zones and other geological structures, there will be cross-section waves on the fault plane, cyclotron waves on the bending interface, and diffraction waves on breakpoints and pinchouts, so the reflected waves from the fault plane or special geological structure plane will be obviously abnormal; when the loose overburden or weathered zone is full of groundwater, its wave velocity will increase obviously, and the diving surface is an obvious wave impedance interface; generally, the velocity and density increase from top to bottom among weathered layers of bedrock. In most cases, there are 3 to 4 velocity or wave impedance interfaces in weathered layers of bedrock, which are consistent with or close to fully weathered, strongly weathered, moderately weathered, weakly weathered and slightly weathered interfaces.

Table 1 Typical rock wave impedance in study area

\begin{tabular}{|c|c|c|c|}
\hline Geotechnical name & Speed/ $\left(\mathrm{m} \cdot \mathrm{s}^{-1}\right)$ & Density $/\left(\mathrm{g} \cdot \mathrm{cm}^{-3}\right)$ & Wave impedance $/\left(10^{4} \mathrm{~g} \cdot \mathrm{s}^{-1} \cdot \mathrm{cm}^{-3}\right)$ \\
\hline Soil & $250-1200$ & $1.1-2.0$ & $2.2-16$ \\
\hline Sand & $300-1500$ & $1.4-2.0$ & $4.2-26$ \\
\hline Clay & $1000-1600$ & $1.5-2.2$ & $27-52.8$ \\
\hline Sandstone & $2000-4000$ & $2.1-2.8$ & $42-112$ \\
\hline
\end{tabular}

\section{IV.Sample Area Selection and Test Setup}

\subsection{Measurement principle and observation method}

The new urban areafor construction in recent yearsis taken as the test sample area. According to the exploration tasks and terrain conditions, the survey lines are reasonably arranged according to local conditions during actual measurement. The length of the survey lines should meet the needs of detecting the thickness and changes of Neogene, finding out the basic structure and its complexity, and preventing missing unknown faults or marginal structures. At the same time, the survey line should be as vertical as possible and cross the main faults. The survey line should be laid in convenient and relatively flat areas without major obstacles as far as possible. It should be laid in a straight line, and various interferences such as underground pipe network should be avoided as far as possible. Meanwhile, the elevation and plane observation errors should meet the requirements.

This survey is conducted by multiple superposition of two-dimensional seismic common reflection points. Acquisition is excited by American M18-60Hz vibroseis, and received by French Sercel-428XL digital seismograph with $0.5 \mathrm{~ms}$ sampling interval and $1.0 \mathrm{~s}$ recording length. The adopted observation system is an observation system with track spacing of $5 \mathrm{~m}$, gun spacing of $30 \mathrm{~m}$, receiving arrangement of 240 tracks, excitation in the middle and coverage frequency of 20 times (Fig.3).

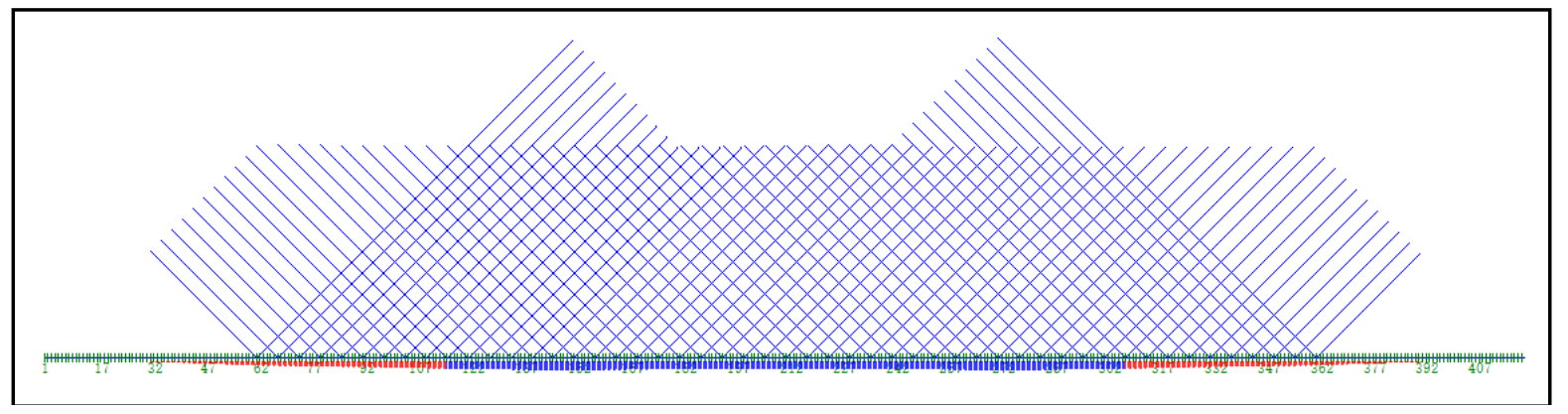

Fig3: Schematic diagram of observation system 
4.2 Data acquisition and optimization processing

For shallow high-resolution seismic prospecting in and around the city, there are many sources of interference waves and large energy. Therefore, it is the key of shallow high-resolution seismic data processing to effectively suppress all kinds of interference waves on the original seismic records, improve the signal-to-noise ratio of the profile, and make all kinds of structural phenomena appear clearly on the profile.

In the process of data processing, this optimization scheme adopts the combination of pre-stack one-dimensional filtering and two-dimensional filtering to suppress interference and improve the signal-to-noise ratio of effective reflected waves; the method of refraction static correction and residual static correction is used to enhance the in-phase of effective reflection and improve the signal-to-noise ratio and resolution of profile. The combination of velocity analysis and velocity spectrum is used to improve the accuracy of calculating superposition velocity; the method of combining pre-stack deconvolution and post-stack migration is used to improve the vertical and horizontal resolution of data. Through the above comprehensive and matching optimization processing technology and repeated experiments, the best processing parameters are selected. The chromatographic static correction datum is $60 \mathrm{~m}$.

\section{Identification and Interpretation of Blind Faults in the Study Area}

\subsection{Interpretation marks of blind faults}

After the original seismic records are processed by indoor data, the seismic reflection time profile which can reflect the characteristics of underground geological structure is obtained. The formation reflection wave groups on the time profile reflect the difference between the underground interface shape and the physical properties of underground formation media. According to the characteristics of reflected wave groups in seismic prospecting profiles and the comparative analysis of geological data, we can determine the seismic wave groups and their relationship with geological horizons. Through careful analysis of the bifurcation, merger, interruption and pinchout of reflected wave groups and the interdependence between reflected wave groups in upper and lower strata, we can get the relationship between these changes and stratum changes, thus obtaining the longitudinal and lateral changes and structural conditions of strata, and identifying faults (position, occurrence, nature, dislocation momentum, upper breakpoint, etc.). At the same time, on the basis of analyzing, comparing and tracing the seismic reflection marker bed on the migration time profile, the blind faults are inferred and interpreted according to the reflected wave field characteristics on the seismic reflection profile and the geological structure characteristics of the survey area. The main criteria for distinguishing blind faults in this area are:

(1) The apparent interruption and dislocation of the reflected wave in-phase axis.

(2) The number of reflected wave in-phase axes obviously increases or decreases or disappears.

(3) The sudden change of the reflected wave in-phase axis shape and reflected wave energy.

(4) Strong phase inversion of the reflected wave in-phase axis and the interdependence between the upper and lower wave groups.

(5) The wave group changes and there is obvious fault, which can be traced continuously after fault interpretation.

(6) Although the in-phase axis can be traced, the whole wave group changes, and the wave group can be consistent after fault interpretation.

(7) The occurrence of abnormal waves (such as diffracted waves and cross-section reflected waves, etc.).

(8) There are obvious differences in stratigraphic occurrence between the hanging wall stratum and the heading wall stratum of the fault.

It should be noted that when the seismic line is perpendicular to the fault strike, the fault occurrence can be determined according to the seismic reflection profile.And when the seismic line crosses the fault strike obliquely, only the apparent occurrence of the fault can be determined by the seismic reflection profile.

5.2 Analysis and interpretation of shallow seismic prospecting results in the study area

ISSN: 0010-8189

(C) CONVERTER 2021

www.converter-magazine.info 
For the test sample area, Hubin New District in the north of the city is selected as the sample area.To cover the test sample area and improve the exploration accuracy, two NE-trending lines (L2, L3) and one NW-trending lines (L1) are arranged in this test sample area, as shown in Fig.5.

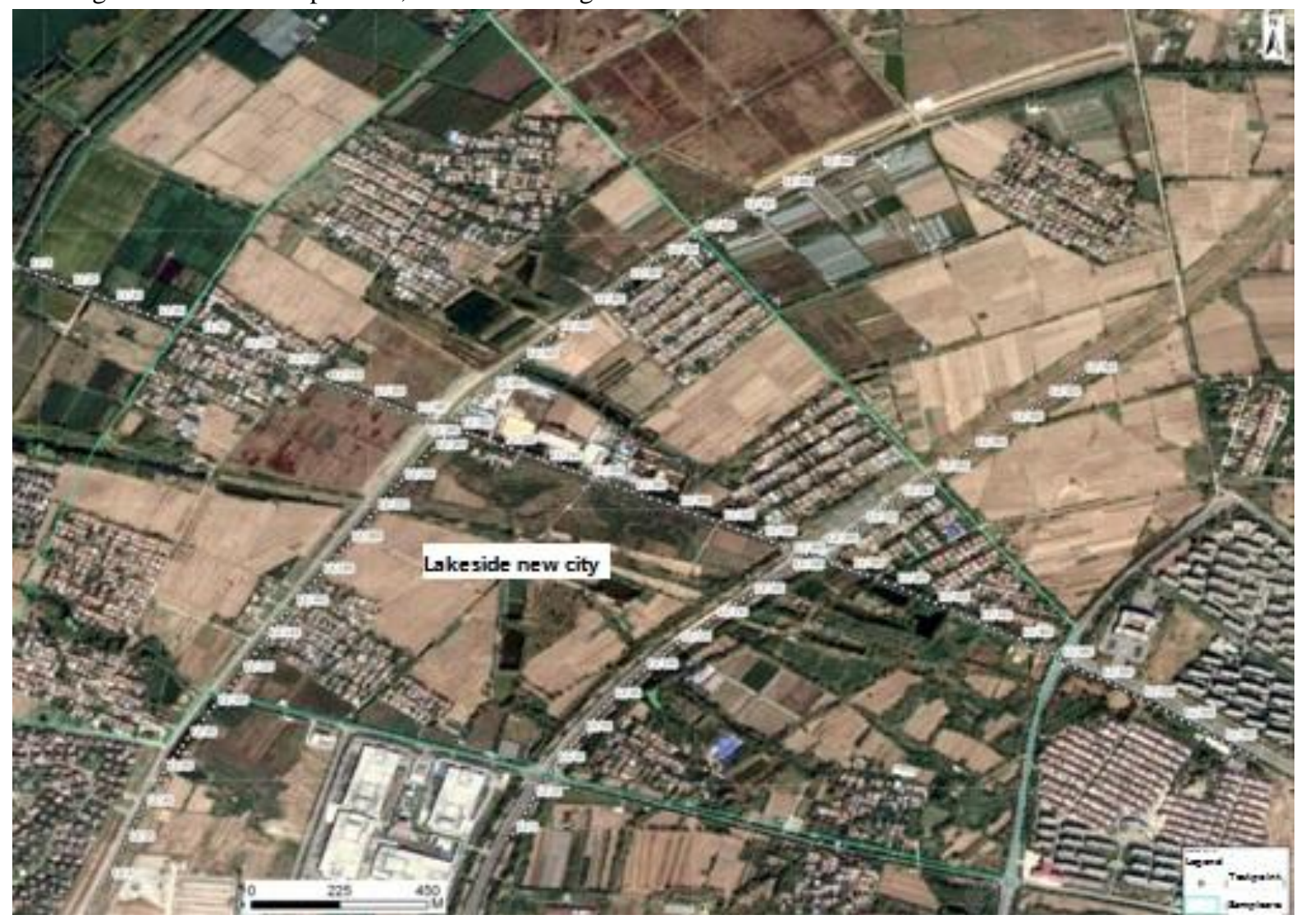

Fig4: Schematic diagram of shallow seismic prospecting survey layout in test target sample area I.

For the study sample area, through fine and repeated debugging of parameters, the results of data correction, noise reduction and optimization of the measurement results of the three survey lines are shown in Fig.5, Fig.6 and Fig.7 According to the seismic reflection time profile, the main target strata have good seismic reflection, clear wave group characteristics and clear faults, which can better reflect the contact relationship of underground strata and meet the needs of subsequent stratigraphic fault interpretation and research.

From the stratigraphic point of view, the Quaternary strata are widely distributed in the whole region, and the characteristics of seismic reflection T3 and TQ change rapidly and have good continuity and strong energy. There is no obvious difference with the underlying strata, showing unconformable contact relationship. The whole area is covered by Quaternary strata, with small lateral thickness change.And the strata are distributed horizontally, mainly in fluvial and lacustrine facies. The thickness of the Quaternary strata changes by $50-100 \mathrm{~m}$ and gradually becomes thicker from east to west; the Quaternary strata directly covers the Cretaceous strata. The Cretaceous stratum is also stepped and thickened from east to west, with thickness varying greatlyfrom 60 to $230 \mathrm{~m}$.

From the perspective of fault combination, although six faults have been interpreted from the shallow seismic prospecting results in the test sample area of the new urban area, based on the comprehensive analysis of the existing drilling holes and geological data, and using the previous seismic results, the section and plane are combined, and the breakpoints with the same properties and similar drops are connected togetheron the premise of conforming to geological laws. Two faults are judged by shallow seismic prospecting in the test sample area of the new urban area, which are $\mathrm{HBF}_{1}$ and $\mathrm{HBF}_{2}$ respectively. See Figure 8 fault interpretation plan of test target sample 
area in new urban area.

According to the interpretation, there are mainly two groups of fault structures in the test sample area. The extension direction of target faults controlled by L1, L2 and L3 survey lines in shallow seismic prospecting is generally EW-trending fault structure and distributed in parallel. The dip angles displayed on the survey lines are relatively large, ranging from $76^{\circ}$ to $81^{\circ}$. The two sets of faults do not cut through Quaternary stratum, but cut through $\mathrm{K} 2 \mathrm{w}$ horizon, in which HBF1 fault distance is $10-25 \mathrm{~m}$ and HBF2 fault distance is $20-40 \mathrm{~m}$. Therefore, this fault belongs to Cretaceous system fault and inactive fault. The sample area of the new urban area is relatively safe, and the earthquake risk coefficient caused by blind faults is low, which can be used as a comprehensive functional area with relatively complete urban functions for planning and construction.

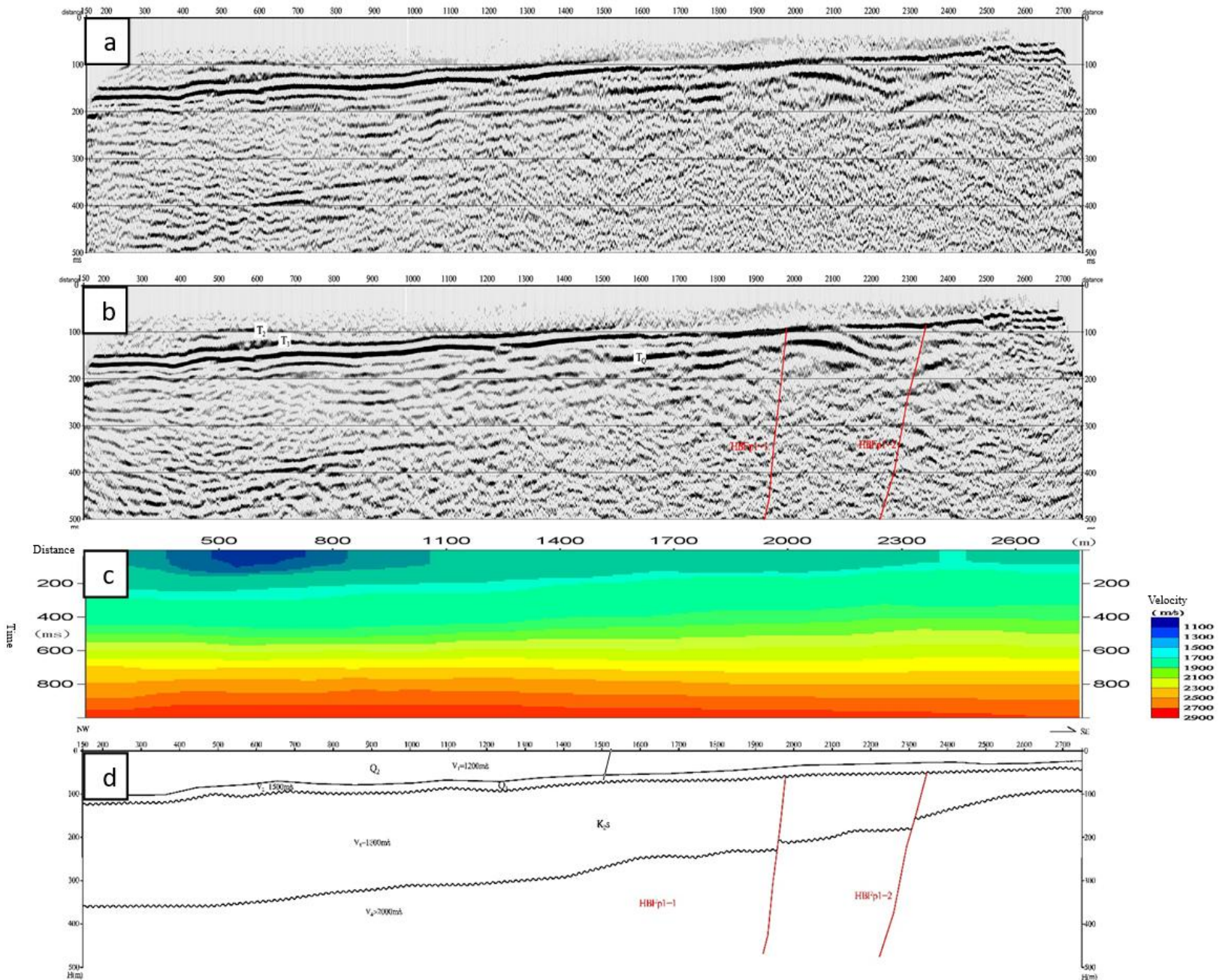

Fig5:Interpretation of seismic reflection time profile, velocity profile and geological profile of L1 survey line. a:Seismic reflection superposition time profile; b:Seismic reflection superposition migration time profile. $c:$ Seismic reflection velocity profile; $d$ :Geological interpretation map.

\section{VI.Conclusions and Suggestions}

Under the condition of strong urban interference, shallow seismic prospecting technology is adopted, and the design scheme is optimized. The northern new urban area of the city is selected as the test sample area, and its measurement, interpretation and identificationare carried out. It is inferred that there are two near-EW faults in the test new area. Seen from the distortion, dislocation and termination of the faults in the middle and lower axes of the seismic reflection profile, the upper continuity is good, which indicates that the faults in this area were mainly active before the Quaternary period and inactive after theQuaternary period.

ISSN: 0010-8189

(C) CONVERTER 2021

www.converter-magazine.info 


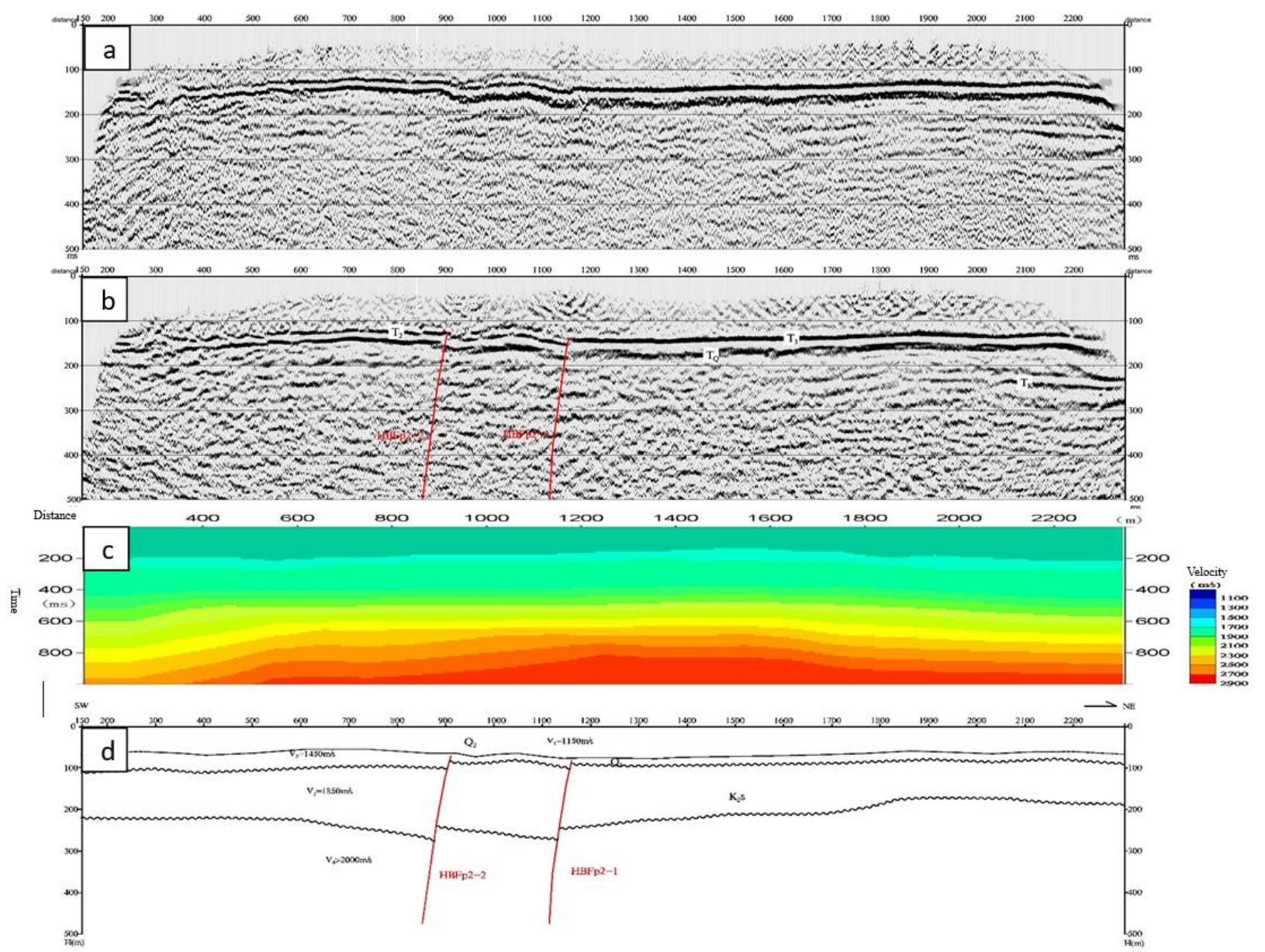

Fig6: Interpretation of seismic reflection time profile, velocity profile and geological profile of L2 survey line. a: seismic reflection superposition time profile; $b$ : seismic reflection superposition migration time profile. c: seismic reflection velocity profile; d:geological interpretation map.

At the same time, because the work site is located in the urban area, the influence obstacles such as highway intersections, roundabout, bridges, villages, factories, and rivers bring inconvenience to the field construction; noise from automobile, factory and construction site has certain influence on data quality.

In the process of data processing, to obtain more shallow seismic information, the near-surface reflected waves include shallow refracted waves, direct waves, reflected waves and other seismic waves, which are cut off near the surface, so it is difficult to distinguish the upper Quaternary strataQ4 and Q3 in shallow areas. In addition, due to the limited drilling data, the geological horizon can only be preliminarily inferred based on the wave group characteristics among the profiles and the interlayer thickness relationship.

Although shallow seismic prospecting technology has advantages in avoiding signal interference, it is suggested that the micro-motion exploration method should be combined with shallow seismic prospecting technology test to improve the recognition degree of near-surface faultsin consideration of the fast spread speed of primary wave and low resolution of near-surface layer.

ISSN: 0010-8189

(C) CONVERTER 2021

www.converter-magazine.info 
CONVERTER MAGAZINE

Volume 2021, No. 5

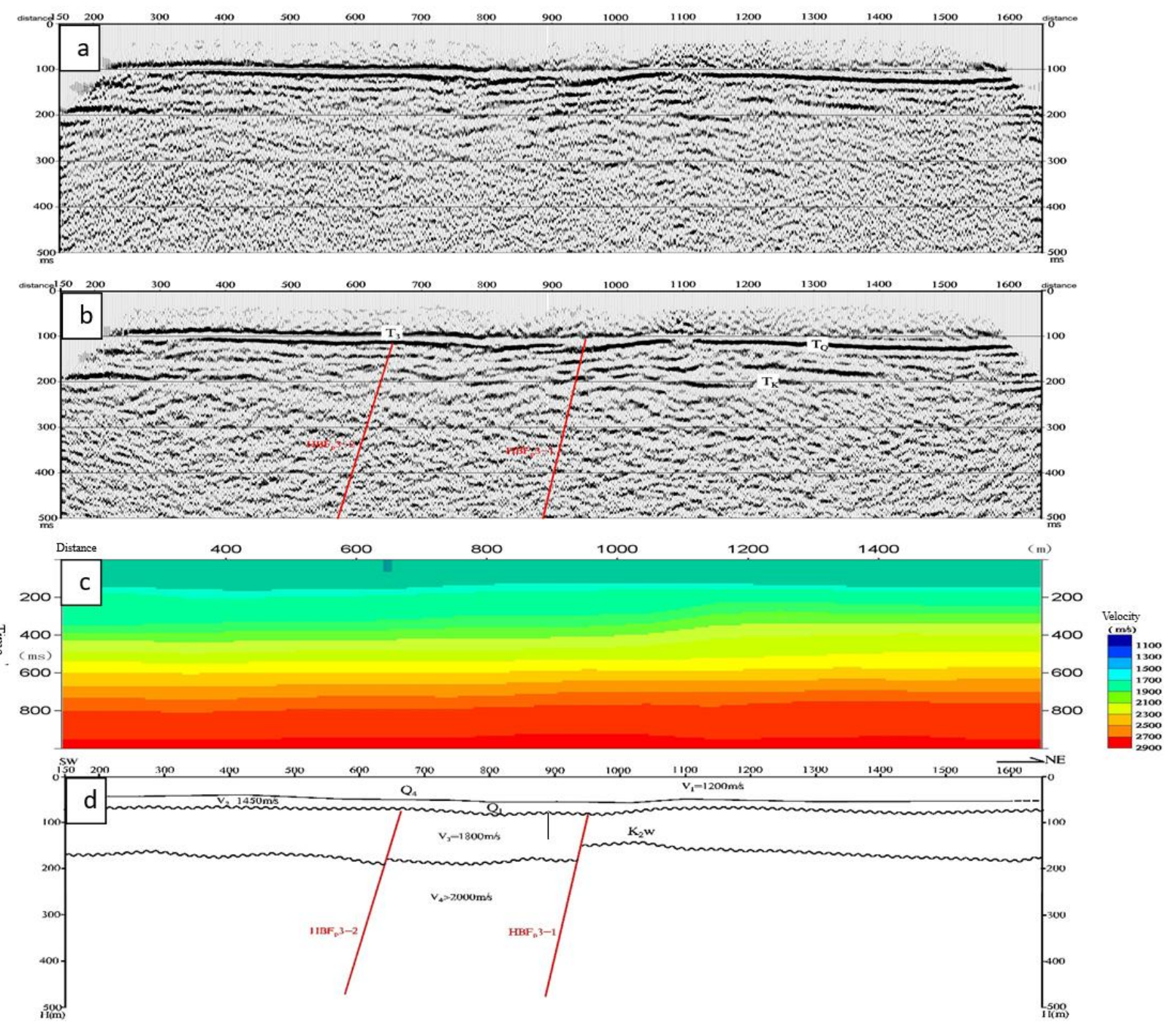

Fig7:Interpretation of seismic reflection time profile, velocity profile and geological profile of L3 survey line. a:seismic reflection superposition time profile; b:seismic reflection superposition migration time profile. c:seismic reflection velocity profile; d:geological interpretation map.

ISSN: 0010-8189

(c) CONVERTER 2021

www.converter-magazine.info 


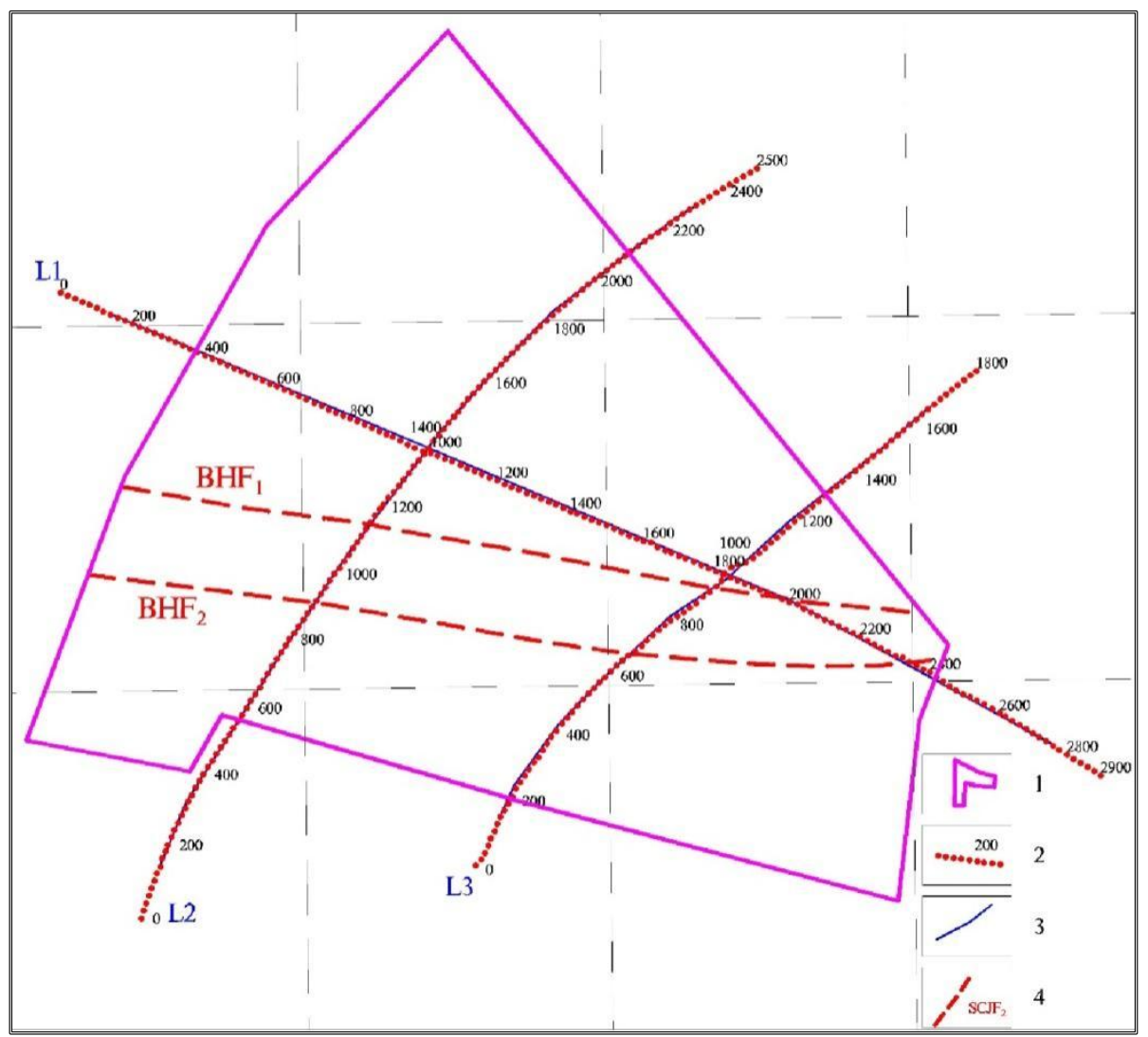

Fig8: Interpretation fracture plan of test sample area in new urban area. 1:Workspace scope. 2:CDP location. 3:Effective results profile. 4:Inferred fault.

\section{References}

[1] Hall JF, Heaton TH, Halling MW, Wald DJ. (1995). Near-source groundmotion and its effects on flexible buildings. Earthquake Spectra, 11(4):569-605. doi: 10.1193/1.1585828.

[2] Somerville PG, Smith NF, Graves RW, Abrahamson NA. (1997). Modification of empirical strong ground motion attenuation relations to include the amplitude and duration effects of rupture directivity. Seismol Res Lett 68(1):199-222. doi:10.1785/gssrl.68.1.199.

[3] Bray JD. (2001). Developing mitigation measures for the hazards associated with earthquake surface fault rupture, in seismic fault-induced failures-possible remedies for damage to urban facilities, Japan Soc.Prom. Sci., K. Konagai, Ed., Univ. of Tokyo, Japan, p55-79.

[4] Ulusay R, Aydan O, Hamada M. (2001). The behavior of structures built on active fault zones: examples from the recent earthquakes of Turkey. In proceedings, A Workshop on Seismic Fault-Induced Failures Possible Remedies for Damage to Urban Facilities. Japan Society for the Promotion of Science, Tokyo, Japan. 1-26.

[5] Wang GQ, Zhou XY, Zhang PZ, Igel H. (2002). Characteristics of amplitude and duration for near fault strong ground motion from the 1999 Chi-Chi, Taiwan Earthquake. Soil DynEarthqEng, 22(1): 73-96. doi:10.1016/S0267-7261(01)00047-1.

[6] Mavroeidis GP, Papageorgiou AS. (2003). A mathematical representation of near-fault ground motions. Bull SeismolSoc Am 93(3):1099-1131. doi:10.1785/0120020100.

[7] Tian YJ, Yang QS, Lu MQ. (2007). Simulation method of near-fault pulsetype ground motion. ActaSeismol Sin 29(1):77-84. doi:10.1007/s11589-007-0080-5.

[8] CaLais E, Freed A, Mattioli G, Amelung F, Jónsson S, Jansma P. (2010). Transpressional rupture of an unmapped fault during the 2010 haiti earthquake. Nature Geoscience. doi: 10.1038/ngeo992.

[9] Zhai CH, Chang ZW, Li S, Chen ZQ, Xie LL. (2013). Quantitative identification of near-fault pulse-like 
ground motions based on energy. Bull SeismolSoc Am 103(5):2591-2603. doi:10.1785/0120120320.

[10] Nie B,Zhao J,Li Y,Mao J,Gu Q. (2015). The Comprehensive Application of Shallow Seismic Prospecting Method to Urban Active Fault Detection. Chinese Journal Of Engineering Geophysicl, 12(001), 15-21. doi: 10.3969/j.issn.1672-7940.2015.01.004.

[11] Ozcelik M, Sarp G. (2017). Soil-structure interaction of existing buildings near the active fault zone (burdur-turkey). Arabian Journal of Geosciences, 10(14), 296. doi: 10.1007/s12517-017-3085-y.

[12] Zhao G, Tang Z, Ren F. (2003). Tow important problems of influence in the survey and evaluation of the buried active fault in city. Earthquake, 023(001), 36-40.doi: 10.3969/j.issn.1000-3274.2003.01.006

[13] Kondo H, Toda S, Okumura K, Takada K, Chiba T. (2008). A fault scarp in an urban area identified by lidar survey: a case study on the itoigawa-shizuoka tectonic line, central japan. Geomorphology, 101(4), 731-739.doi: 10.1016/j.geomorph.2008.02.012.

[14] Somerville P, Quijada P, Hong KT, Sandiford M, Quigley M. (2008). Contribution of identified active faults to near fault seismic hazard in the Flinders Ranges.

[15] Iwahashi J. (2010). 1:25,000-scale active fault map in urban areas published by gsi. Bulletin of the geospatial information authority of japan, 29-37.

[16] Tsutsumi H, Perez JS. (2013). Large-scale active fault map of the philippine fault based on aerial photograph interpretation. Active Fault Research, 29-37.doi: 10.11462/afr.2013.39_29.

[17] Burjánek J, DonatFh, Michel C, Lguer DL, Karbassi A. (2012). Earthquake Damage Scenario in Visp (Switzerland): From Active Fault to Building Damage. World Conference on Earthquake Engineering.

[18] Pavlides S, Tsapanos T, Zouros N, Sboras S, Koravos G, Chatzipetros A. (2009, October). Using active fault data for assessing seismic hazard: a case study from NE Aegean sea, Greece. In Earthquake Geotechnical Engineering Satellite Conference XVIIth International Conference on Soil Mechanics \& Geotechnical Engineering 2e3 (Vol. 10, p. 2009).

[19] Kiyomine T, Itsuki, N. (2011). Feasibility and Problems of Earthquake Disaster Reduction Measures Based on Active Fault Data. Journal of Earthquake and Tsunami, 5(01), 19-29.

[20] Guerrieri L, Leoni G, Blumetti AM, Comerci V. (2014). Fault Displacement Hazard in urban areas in Italy: a first assessment. In Proceedings of the 5th International INQUA Meeting on Paleoseismology, Active Tectonics and Archeoseismology (PATA) (pp. 21-27).

[21] Stanciu I, Ioane D. (2016, November). Active Fault Systems in TheShabla Region (Bulgaria) As Interpreted on Geophysical and Seismicity Data. In Paper presented at the 1st GEOSCIENCE Symposium of the Romanian Society of Applied Geophysics. doi: 10.5281/zenodo.4543084.

[22] Barrile V, Fotia A. (2019). Seismic Risk: GPS/GIS Monitoring and Neural Network Application to Control an Active Fault in the Castrovillari Area (South Italy). ArcHistoR, 6(12), 570-583. doi: 10.14633/AHR182.

[23] Baskoro WT, Warnana DD, Widodo A, Rochman JPGN, Santosa BJ. (2019, November). Preliminary site characteristics for urban seismic hazard in pasuruan fault from microtremor measurements. In IOP Conference Series: Earth and Environmental Science (Vol. 389, No. 1, p. 012004). IOP Publishing.

[24] Wushouaili R. (2019). Danger Assessment and Geophysical Exploration Methods for Urban Active Faults. ActaGeologica Sichuan, (02), 232-236. doi: 10.3969/j.issn.1006-0995.2010.02.027

[25] Peng C, Chen XQ, Zhu YY, Su FH, Wei FQ, Han YS. (2011). Thewenchuan earthquake (may 12, 2008), sichuan province, china, and resulting geohazards. Natural Hazards, 56(1), 19-36. doi: 10.1007/s11069-009-9392-1

[26] Larroque C, Delouis B, Hippolyte JC, Deschamps A, Lebourg T, Courboulex F, Bellier O. (2011). Joint multidisciplinary study of the Saint-Sauveur-Donareo fault (lower Var valley, French Riviera): a contribution to seismic hazard assessment in the urban area of Nice. Bulletin de la Sociétégéologique de France, 182(4), 323-336. doi: 10.2113/gssgfbull.182.4.323

[27] Zhang P, Li L, Xu H, Liu J, Li J, Gu Q, Wang J, Jiang X. (2014). Identification of Fault Activity in Urban Active Fault Exploration and Seismic Risk Assessment in Xuzhou City. Technology for Earthquake Disaster Prevention, 9(4), 801-812. Doi: 10.11899/zzfy20140407

[28] Ioane, D., Diaconescu, M., Chitea, F., \&Garbacea, G. (2014). Active fault systems and their significance 
for urban planning in Bucharest, Romania. In Earthquake hazard impact and urban planning (pp. 15-43). Springer, Dordrecht.

[29] Imposa S, De Guidi G, Scudero S, Grassi S. (2015). Fault rupture hazard along a sector with aseismic creep in urban area (Eastern Sicily). Georisks in the Mediterranean and Their Mitigation, 102-109.

[30] Xia C, Qi C, Zhao B, Qu X. (2019). Seismic response of the subway station due to a specific active fault. Tunnelling\& Underground Space Technology, 85, 12-20.doi: 10.1016/j.tust.2018.11.033

[31] Suzuki, Y. (2020). Active fault and earthquake disasters. In Human Geoscience (pp. 99-117). Springer, Singapore.

[32] Liu ZY,WeiYF,Tan D, Han YB, Zhang H, Liu GH. (2020). Application of shallow seismic in detecting Quaternary concealed small faults. Chinese Journal of Engineering Geophysics, 17(3):308-311.

[33] Guan ZB. (2021). Research on shallow seismic exploration technology. West-china Exploration Engineering, (6):111-119.

[34] Demanet D, Renardy F, Vanneste K, Jongmans D, Meghraoui M. (2001). The use of geophysical prospecting for imaging active faults in the roergraben, belgium. Geophysics, 66(1), 78-89. doi: $10.1190 / 1.1444925$

[35] Kaiser AE, Green AG, Campbell FM, Horstmeyer H, Manukyan E, Langridge RM, Nobes DC (2009). Ultrahigh- resolution seismic reflection imaging of the Alpine Fault, New Zealand. Journal of Geophysical Research: Solid Earth, 114(B11). doi: 10.1029/2009JB006338

[36] PM, Pondard N. (2013). Derivation of direct on-fault submarine paleo earthquake records from high-resolution seismic reflection profiles: Wairau fault, New Zealand. Geochemistry Geophysics Geosystems, 11(11), 1-22. doi: 10.1029/2010GC003254

[37] Gu QP, Kang QQ, Xu HG, Zhang ZY, Zhao QG, Meng K. (2017). New evidence from shallow seismic surveys for Quaternary activity of the benchahe fault. Journal of Geophysics \& Engineering, (4), 1-17. doi: 10.1088/1742-2140/aaa158

[38] Liang K, Sun C, Ma B, Tian Q, Li D, He Z. (2018). Investigation of the yellow river blind fault in the wuhai basin, northwestern ordos block, china, using deep/shallow seismic reflection and drilling techniques. Journal of Asian Earth ences, 163(SEP.1), 54-69. doi: 10.1016/j.jseaes.2018.05.025

[39] Onyebueke EO, Manzi MSD, Durrheim RJ. (2018). High-resolution shallow reflection seismic integrated with other geophysical methods for hydrogeological prospecting in the Nylsvley Nature Reserve, South Africa. Journal of Geophysics and Engineering, 15(6), 2658-2673. doi: $10.1088 / 1742-2140 /$ aadbe3 